\title{
Optic nerve avulsion after blunt ocular trauma - Case report
}

\author{
Jerzy Mackiewicz', Joanna Tomaszewska', Monika Jasielska' \\ ${ }^{1}$ Department of Vitreoretinal Surgery, Medical University, Lublin, Poland
}

Mackiewicz J, Tomaszewska J, Jasielska M. Optic nerve avulsion after blunt ocular trauma - Case report. Ann Agric Environ Med. 2016; 23(2): 382-383. doi: 10.5604/12321966.1203911

\begin{abstract}
Introduction. Avulsion of the optic nerve head is a rare and severe complication of ocular blunt trauma. The case reported is a 28-year old man presenting to the emergency department due to blunt trauma to his right eye globe with a tree branch. Lid haematoma and subconjunctival haemorrhage were present. Visual acuity soon after the injury was counting fingers (CF) and on admission to the Department of Ophthalmology he had no light perception (NLP). Fundus examination revealed prepapillary haemorrhage, which after few days dispersed into the vitreous cavity. Despite no light perception in the affected eye, the patient was qualified for vitrectomy. During surgery, an optic nerve avulsion with cicatricial gliosis was diagnosed. Six months after vitrectomy, the visual acuity was NLP in the right eye.

Discussion. The clinical signs, mechanism, treatment and natural history of this poorly known disease are described.

Conclusion. Optic nerve avulsion must be considered in cases of trauma with forced rotation of the eye. Damage occurring at the disc may suggest mechanisms involving anterior luxation of the globe, retropulsion of the nerve, forced globe rotation, or a sudden explosive rise in intraocular pressure blowing the nerve off the sclera into its dural sheath. Damage and break of the nerve fibres are responsible for immediate visual impairments, and involving secondary haematomas and oedemas In spite of required safety precautions in agriculture work, eye injuries are still prevalent. Blunt ocular trauma remains a large part of this group, leading even to irreversible blindness.
\end{abstract}

Key words

traumatic optic neuropaty, blunt ocular trauma, eye injuries, optic nerve avulsion

\section{INTRODUCTION}

Avulsion of the optic nerve head is a rare and severe complication of ocular blunt trauma. Damage to the optic nerve can be caused by number of mechanisms, usually involving damage in the canal or in the orbit; the intracranial part of the nerve is rarely involved because of its mobility. It may occur due to extension of bone fracture, direct penetration of a foreign body, or by shearing forces tearing the pial sheath of the nerve. Traumatic damage may also concern the disc. The mechanism responsible for this type of injury may be anterior luxation of the globe, retropulsion of the nerve, forced globe rotation, or a sudden explosive rise in intraocular pressure blowing the nerve off the sclera into its dural covering, like a cork from a bottle [1]. The loss of myelin and absence of supportive connective tissue septae make the axons at lamina cribrosa particulary vulnerable [2].

\section{CASE REPORT}

We present a case of 28 -year old man admitted to the emergency service due to blunt trauma to his right eye with a fruit tree branch while driving a tractor. The accident took place in the orchard while pesticides were being used as prevention. At the initial examination, a lid hematoma and subconjunctival haemorrhage were present. The head X-ray did not reveal fractures of the bones. Computed tomography of the head was performed. High resolution brain and

Address for correspondence: Joanna Tomaszewska, Department of Vitreoretinal Surgery, Medical University, Lublin, Chmielna 1, 20-079 Lublin, Poland E-mail: joantomaszewska@yahoo.pl

Received: 14 May 2014; accepted: 11 September 2014 orbital scans revealed a slightly enlarged optic nerve in its retrobulbar part $(6 \mathrm{~mm}$, compared to the $5 \mathrm{~mm}$ optic nerve in the other eye). Visual acuity was counting fingers at 1 meter in the right eye and 20/20 in the left. The left eye was normal. Slit-lamp examination revealed a subconjunctival haemorrhage of the right eye. The cornea and lens were intact and clear and fundus examination showed a prepapillary haemorrhage. After several days, visual acuity decreased to 'no light perception' (NLP) and the preretinal haematoma spontaneously dispersed into the vitreous cavity. Mild peripapillary oedema and choroidal folds were observed. Patient received a high dose of intravenous steroids, although he failed to respond. One week after trauma, the patient was referred to the Ophthalmology Department in Lublin,

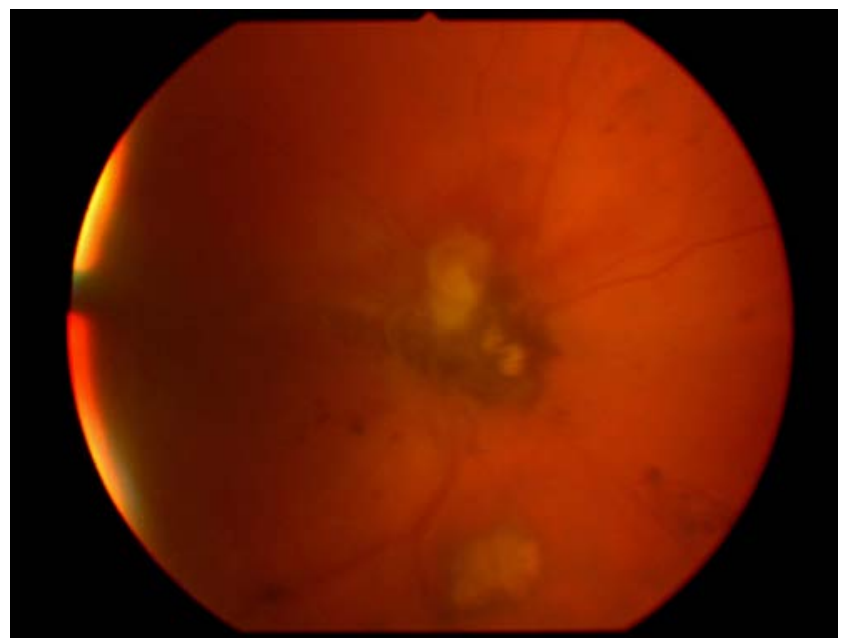

Figure 1. Colour fundus photography showing optic nerve avulsion 
and fundus examination showed a vitreous haemorrhage. Ultrasound examination also showed retinal detachment. Due to the persistence of an intravitreal haemorrhage and lack of visual recovery, a vitrectomy with lensectomy was performed 2 months later, leading to the diagnosis of an optic nerve avulsion with cicatricial gliosis. Six months after vitrectomy, the visual acuity was NLP in the right eye.

\section{DISCUSSION}

The clinical signs, mechanism, treatment and natural history of this poorly known disease are described. According to Pirouzmand [3], motorized vehicle accidents remain the main etiology of traumatic optic neuropathy (TON) (63\%). The respective demographics for TON group were as follows: male, 76\%; median for age, 33.5 years. Optic nerve avulsion must be considered in cases of trauma with forced rotation of the eye. The damage occurring at the disc may suggest mechanisms involving anterior luxation of the globe, retropulsion of the nerve, forced globe rotation, or a sudden explosive rise in intraocular pressure blowing the nerve off the sclera into its dural sheath. Damage and break of the nerve fibres are responsible for immediate visual impairments and involving secondary haematomas and oedemas [4]. Buchwald et al. [5] classifies the mechanism of traumatic optic neuropathy as primary or secondary. Primary damage occurs as a result of external forces at the moment of trauma, e.g., rupture of nerve fibres or of capillary vessels. Secondary damage may not be present initially, but may occur later and results from the compromised blood supply to the optic nerve, e.g., following oedema or angiospasm [5]. In a study of 182 patients suffering from penetrating eye trauma, $15.6 \%$ were work-related agriculture penetrating eye injuries. Visual outcome remained very poor at final review ( $64 \%$ were blind) [6].

In spite of required safety precautions in agriculture work, eye injuries are still prevalent. Blunt ocular trauma remains a large part of this group, leading even to irreversible blindness.

\section{REFERENCES}

1. Hillman J, et al. Complete avulsion of the optic nerve Brit J Ophthal. 1975; 59: 503 .

2. Anand S, Harvey R, Sandramouli S. Accidental self-inflicted optic nerve head avulsion. Eye (Lond). 2003 Jul; 17(5): 646-7.

3. Pirouzmand F. Epidemiological trends of traumatic optic nerve injuries in the largest Canadian adult trauma center. J Craniofac Surg. 2012 Mar; 23(2): 516-20.

4. Balla L, Ianovici N, Costin D. Pathology of the optic nerve injury. Rev Med Chir Soc Med Nat Iasi. 2012 Oct-Dec; 116(4): 1087-90.

5. Buchwald HJ, Weingärtner WE, Spraul CW, Wagner P, Lang GK. [Contusion of the optic nerve after minor blunt ocular trauma: case report and literature review]. Ophthalmologe. 1999 Aug; 96(8): 529-33.

6. Mackiewicz J, Machowicz-Matejko E, Sałaga-Pylak M, PiecykSidor M, Zagórski Z. Work-related, penetrating eye injuries in rural environments. Ann Agric Environ Med. 2005; 12(1): 27-9. 